\section{O léxico nas traduções de história em quadrinhos: uma experiência baseada em corpus}

\section{Lexicon in comics translations: an experience based on corpus}

Elaine Cristina Ferreira de OLIVEIRA (UNESP) elaininha.hta@hotmail.com Adriane Orenha OTTAIANO (UNESP) adrianeorenha@gmail.com Vinicius Cineli ALVES (UNESP) vinnycineli@yahoo.com.br
OLIVEIRA, Elaine Cristina Ferreira de; OTTAIANO, Adriane Orenha; ALVES, Vinicius Cineli. O léxico nas traduções de história em quadrinhos: uma experiência baseada em corpus. Entrepalavras, Fortaleza, v. 7, p. 141-159, jan./jun. 2017.

Resumo: Esta investigação conta com o arcabouço teórico-metodológico da Linguística de Corpus, de trabalhos acerca de corpora de aprendizes, bem como de pesquisas baseadas na abordagem lexical. Nesta pesquisa, descrevemos um exercício de tradução de História em Quadrinhos da Turma da Mônica, do português para a língua inglesa, realizado por alunos de uma escola particular profissionalizante na cidade de Votuporanga, região noroeste do Estado de São Paulo. A compilação destes dados foi organizada em arquivos e deu origem a um corpus de aprendizes paralelo, aqui denominado CALI-TradHQ (Corpus de Aprendizes de Língua Inglesa - Tradução de História em Quadrinhos). A metodologia se ocupa da compilação das traduções e do tratamento dos dados no formato eletrônico pelo uso do software WordSmith Tools. Desse modo, este artigo visa mostrar de que forma nós, professores de Língua Estrangeira (LE), podemos utilizar corpora para compreender como os alunos brasileiros utilizam a língua inglesa, notadamente no tratamento e no emprego do léxico. No item análise de dados, investigamos as escolhas efetuadas pelos discentes para traduzir determinados itens lexicais e expressões idiomáticas e discutimos a importância do uso de um corpus de aprendizes de traduções.

Palavras-chave: Linguística de Corpus. Corpora de Aprendizes. História em Quadrinhos. 
v. 7 (1)

141-159 jan/jun 2017

Abstract: This research has the theoretical-methodological framework of Corpus Linguistic, of investigations on Learner Corpora, as well as studies based on the Lexical Approach. In this article, we describe an exercise of translation of Turma da Monica comics, from Portuguese into English, performed by students of a private school education in the city of Votuporanga, in the northwest region of the State of São Paulo. The compilation of this data was organized into files and gave rise to a corpus of learners parallel, here called CALI-TradHQ (Corpus of Learners of the English Language - Translation of Comic Books). The methodology is concerned with the compilation of translated texts and processing of data in electronic format by using the software WordSmith Tools. Thus, this article aims to show how we, foreign language teachers can use corpora to understand how Brazilian students use the English language, notably in the treatment and employment of the lexicon. In the item data analysis, we investigate the choices made by students to translate some specific lexical items and idioms and discussed the importance of using translation learner corpora.

Keywords: Corpus Linguistics. Learner Corpora. Comic Books.

\section{Introdução}

Neste artigo, visamos descrever a aplicação de uma atividade de tradução de história em quadrinhos, que consiste na tradução do português para a língua inglesa de histórias em quadrinhos da Turma da Mônica, realizada por alunos de uma escola particular profissionalizante na cidade de Votuporanga. Após a realização desta atividade, compilamos um corpus de aprendizes paralelo, denominado CALI-TradHQ (Corpus de Aprendizes de Língua Inglesa - Tradução de História em Quadrinhos), formado pelas traduções dos referidos alunos.

Esta pesquisa objetiva também analisar os dados computados pelas ferramentas eletrônicas, a saber, o software WordSmith (versão 6.0), acerca das escolhas lexicais dos estudantes na atividade da tradução de determinados itens lexicais e expressões idiomáticas da língua portuguesa para a inglesa.

Busca-se, assim, refletir se a abordagem pedagógica empregada no curso de línguas do grupo de alunos em estudoé eficaz em seupropósito de proporcionar que os estudantes atinjam os patamares esperados de aprendizagem para uma turma de nível B1.

A justificativa se dá pelo entendimento de que, ao aprender uma segunda língua, o aluno precisa compreender as nuances existentes em cada código.

Consequentemente, a relevância deste artigo ainda diz respeito à disseminação da linha de pesquisa Pedagogia do Léxico e da Tradução Baseada em Corpora, dentro da área de Estudos Linguísticos. Apesar 
de ser uma área em crescente atividade no Brasil e no exterior (notadamente no continente europeu), seus estudos e pesquisas ainda são desconhecidos pelo grupo de estudantes, pesquisadores e docentes dos cursos de Letras, Línguas e Tradução.

\section{0 uso de atividades de tradução em sala e a importância da abordagem lexical}

Ao longo da história do ensino de línguas, constatavam-se diversas mudanças nos métodos desenvolvidos para o ensino de línguas. Richards e Rodgers (1986) explicam que estas mudanças nos métodos de ensino acontecem em função do reconhecimento de alterações refletidas no tipo de proficiência que os alunos precisam.

Surge, assim, no final do século XVIII, uma das abordagens mundialmente conhecida e disseminada: o Método de Gramática e Tradução ou Método Clássico. Seus principais traços incluem o foco nas regras gramaticais, memorização de vocabulário e de várias declinações e conjugações, traduções de textos e exercícios escritos.

É preciso considerar as dificuldades dos alunos em transferir informações de um idioma para o outro, ainda mais em se tratando de alunos que estudam LE há poucos anos. Entre alguns percalços, destacam-se lidar com as diferenças lexicais de cada sistema ou código, observar ocorrências de certos padrões e compará-los com a língua em estudo, entre outras questões de adequabilidade.

A Tradução e suas contribuições no ensino de LE têm sido tema de diversas discussões no meio acadêmico, que enxergou neste assunto um método em potencial a ser estudado pela Linguística Aplicada.

Por outro lado, faz-se necessário abordar o papel do léxico na aquisição de um idioma. Afinal, devemos considerar as dificuldades enfrentadas pelos alunos, em especial os iniciantes no curso de idiomas, aoefetuar a transição entre um vernáculo e outro - comprometendo a identidade do texto e os sentidos que dele se depreendem.

Segundo Venturi (2006), os alunos tendem a não compreender as regras gramaticais em um primeiro momento. Por isso, é profícuo intercalar conteúdos lexicais e gramaticais, à medida que os discentes demonstram maturidade em avançar neste contexto.

As combinações de palavras citadas são importantes para a aquisição de uma LE, pois, enquanto os discentes tecem reflexões sobre 
v. 7 (1)

$141-159$ jan/jun 2017

o idioma alvo, paulatinamente ampliam o conhecimento cultural e linguístico acerca da língua inglesa e suas características adjacentes.

O tempo das aulas, contudo, é muito limitado para garantir um trabalho proveitosode expansão de vocabulário. Por isso, atividades diferenciadas e significativas para os alunos proporcionam excelentes situações de aprendizagem real dentro da sala de aula.

Tal discussão é pertinente, pois sabe-se que muitas vezes os alunos são dependentes do material didático fornecido pela instituição escolar e, quando se deparam com situações comunicativas, possuem dificuldades para organizar seu pensamento em LE de forma autônoma.

\section{A linguagem à luz da Linguística de Corpus (LC)}

A LC surgiu da necessidade que os pesquisadores tinham em incluir o uso real da língua nos estudos linguísticos. Tal área de estudo está associada ao uso do computador por meio de ferramentas eletrônicas, de forma que, ao compilar os corpora, seguimos com a descrição e interpretação de dados autênticos.

Por esse motivo, analisa a língua por um viés empírico, assumindo padrões demonstrados por estruturas identificáveis nos dados coletados. Seu objeto de estudo, assim, é o corpus linguístico (autêntico e capaz de atestar a representatividade da língua).

Visto já existir uma bibliografia extensa de LC ${ }^{1}$, esse texto tratará com mais ênfase sobre as particularidades dos estudos com corpora e corpora de aprendizes.

Segundo Sinclair (1997, p.31) "Language cannot be invented; it can only be captured"2. Esta frase icônica nos chama a atenção para o caráter "analítico e questionador" desta vertente teórica, pois 'capturar a linguagem' significa olhar as variantes possíveis e identificar quais são as escolhas mais eficazes no processo de comunicação. Também assume que a mudança e a variação linguística se fazem presentes na linguagem, descrevendo assim, os padrões léxico-gramaticais do código.

\footnotetext{
1 Por atuar em diversas frentes disciplinares, a LC abrange métodos variados, responsáveis por investigar inúmeros paradigmas dentro de contextos distintos. Suas análises também possibilitam a aplicação em diferentes segmentos, respectivamente na Aprendizagem de Língua Estrangeira, Estudos da Tradução, Corpora de Aprendizes, Fraselogia de língua comum e especializada, dentre outras vertentes.

2 Em português: "A linguagem não pode ser inventada; ela somente pode ser capturada". Todas as traduções são de responsabilidade dos autores.
} 
Outra característica do estudo envolvendo corpora tange ao caráter quantitativo e qualitativo das análises. Neste sentido Viana (2010, p. 35) postula que devido a peculiaridade das informações advindas dos softwares aliados aos dados matemáticos, o trabalho com corpora naturalmente envolve um teor estatístico - já que são resultados dos próprios itens manuseados pelo computador.

Contudo, além das informações exatas, o que irá demonstrar a riqueza da pesquisa será a forma como a expressão linguística será verificada qualitativamente. Ou seja, aidentificação dos padrões existentes na linguagem coletada, a reflexão sobre termos de comunicabilidade e intencionalidade do falante, culminando, mais adiante, nas relações semânticas entre tais padrões observados.

A partir da LC e do advento do uso de corpora de aprendizes para o ensino de línguas, esta recente área da Linguística Aplicada vem destacando-se eficazmente no ensino de LE. Na literatura brasileira, por exemplo, é possível encontrar trabalhos interessantes como o de Orenha-Ottaiano e Rocha (2015). Com base em um corpus paralelo, compilado a partir das legendas bilíngues do seriado House M.D., os autores propõem atividades pedagógicas para as aulas de inglês, já que uma das vertentes do uso de corpora é exatamente em aulas de idiomas, como foco no ensino de vocabulário.

Dessa forma, se instruído de forma segura, o estudante buscará por si só os padrões de uso, bem como significado de palavras e expressões, classes gramaticais e demais padrões linguísticos.

\section{As contribuições dos Corpora de Aprendizes no ensino de LE}

Tribble (1990) foi um dos precursores na utilização de pequenos corpora de aprendizes ao investigar a relação de verbos usados na fala de seus alunos. Outro estudo nesta área é o de Granger e Tribble (1998): os autores confrontaram o subcorpus francês do ICLE³ e um subcorpus deummilhão de palavras do BNC4.

McEnery e Wilson (1997, p.104) defendem o uso deste recurso, afirmando:

\footnotetext{
3 É a sigla de The International Corpus of Learner English. Na Website da Université catholique de Louvain, é possível conhecer mais informações sobre a segunda versão este trabalho, em inglês: <https://uclouvain.be/en/research-institutes/ilc/cecl/iclev2. html>. Acesso em: 30 jul. 2017.

${ }^{4}$ BNC. British National Corpus. Distributed by Oxford University Computing Services on behalf of the BNC Consortium. Disponível em: <http://www.natcorp. ox.ac.uk/ $\geq$. Acesso em: 30 nov. 2016.
} 
v. 7 (1)

Os exemplos com corpus são importantes para a aprendizagem de idiomas, uma vez que expõem os alunos em uma fase precoce do processo de aprendizagem aos tipos de frases e vocabulário que vão se deparar na leitura de textos autênticos ou ainda no uso da língua em situações reais de comunicação. ${ }^{5}$

Leech (1998) destaca, ainda, que por intermédio de corpora é possível compreendermos como os estudantes se expressam em um idioma estrangeiro, sobretudo no que diz respeito à interlíngua - uma fina linha extremamente tênue entre os vernáculos envolvidos.

O professor tem, então, uma alternativa computacional que possibilita ao aluno ter acesso ao uso da língua em situações reais de interação. Neste âmbito, o professor possibilitará ao seu grupo de alunos compreender o idioma em estudo nas situações reais e naturais de comunicação.

Orenha-Ottaiano (2012, 2016), por sua vez, propõe o desenvolvimento de atividades pedagógicas de LE em uma plataforma on-line. O ineditismo da pesquisa é louvável, pois, a partir da compilação de corpora de aprendizes, é possível explorar diversas colocações. Além disso, as possibilidades de acesso a tais informações são ampliadas, pelo rol de acessos de estrangeiros à página da web.

Para superar este desafio, é necessário que o estudante não nativo possua autonomia, indagando o porquê de certas estruturas linguísticas prevalecerem em detrimento de outras. É no cenário de emprego de novas tecnologias que o uso de corpora propõe uma nova visão em relação à tradicional aula de idiomas.

De posse deste saber, é fundamental que o professor de LE prepare atividades que otimizem o desenvolvimento léxico-gramatical em seus discentes. Uma das alternativas é o uso de tarefas de tradução em sala de aula, bem como a exploração dos textos traduzidos pelos alunos, os quais formam um corpus de aprendizes de tradução, a fim de que se afira a conscientização das habilidades cognitivo-discursivas dos discentes em relação à língua-alvo, com foco no léxico, por meio de uma abordagem lexical, conforme descrita neste trabalho.

O estudo baseado em corpus, portanto, possibilita ao aluno testar as hipóteses e sintetizar conhecimentos, pois mescla o empirismo ao instrumental.

\footnotetext{
${ }^{5}$ No original: "Corpus examples are important in language learning as they expose students at an early stage in the learning process to the kinds of sentences and vocabulary which they will encounter in reading genuine texts in the language or in using the language in real communicative situations."
} 
Portanto, outra informação relevante a respeito das pesquisas baseadas em corpora é o uso de corpus paralelo. Frankenberg-Garcia (2008) caracteriza esta vertente como textos cujas traduções são contrastadas com a escrita original. O objetivo é verificar como os aprendizes encontram termos lexicais correspondentes. A análise das informações e sua respectiva interpretação são utilizadas tanto por pesquisadores da área de tradução, que identificam padrões linguísticos relevantes de acordo com as questões de pesquisa levantadas, quanto por docentes de LE.

Outra ênfase necessária a ser feita no escopo deste artigo é acerca do gênero textual escolhido para a produção dos discentes. Assim, o próximo tópico faz incursões sobre o mundo da História em Quadrinhos e sua relevância como ferramenta de interação e identidade cultural para o estudante.

\section{Gênero História em Quadrinhos no Ensino e Aprendizagem de LE e as particularidades para a tradução}

Os quadrinhos causam um impacto positivo sobre os hábitos de aprendizagem de muitos estudantes, uma vez que a arte sequencial apresenta a poderosa combinação entre literatura e entretenimento visual.

Estes fatores nos levam a considerar as histórias em quadrinhos (doravante HQ) como um recurso muito útil e acessível para confrontar as dificuldades de aprendizagens dos discentes, já que permitem uma série de atividades com as quais podemos exercitar a observação, a percepção, a memória, a atenção e a capacidade de programar e controlar seus progressos.

Barbosa e Vergueiro (2004, p. 22) indicam que a relação entre verbal e pictórico é responsável por otimizar o entendimento de conceitos que outros códigos separados não conseguiriam fazer.

Acerca da tradução deste gênero, há de se considerar que, ao lidar com HQs, além de signos verbais, o tradutor/aluno lida também com signos não verbais, os quais não possuem significado universal.

Para lidar com cada um desses elementos, o tradutor ou o aluno que se incursa nesta empreita deve, além de conhecer o código linguístico, saber o que encontrará neste âmbito, tais como os aspectos sociais, políticos e culturais da cultura de chegada, especificamente aspectos da sua própria cultura. 
v. 7 (1)

141-159 jan/jun

Segundo o autor Zanettin (2009):

A tradução dos quadrinhos é diferente da 'tradução habitual' não só porque as palavras coexistem com o sistema não verbal, mas também porque a linguagem verbal nos quadrinhos é somente parte - e às vezes é a única parte visível (isto é na tradução) - do que conseguem traduzir. ${ }^{6}$

Assim, os quadrinhos, quando traduzidos, devem ser adaptados extralinguística e linguisticamente para irem aoencontro das expectativas do público-alvo. Com isso reitera-se que o processo tradutório das HQs é complexo e exige do tradutor/aluno pesquisa, trabalho e paciência.

Desta forma, por meio do exercício de tradução aplicado a aprendizes de língua inglesa, analisaremos e apontaremos os traços oriundos do processo de tradução, bem como observaremos a forma com que os discentes realizaram as adequações lexicais na língua-alvo, levando em conta os recursos oferecidos pelo gênero.

\section{Caracterização da escola e dos agentes participantes da pesquisa}

Há 148 alunos de inglês na Escola de Ensino Profissionalizante Microlins, oriundos de escolas públicas e particulares do município de Votuporanga e região. O curso de inglês da unidade escolar é oferecido ao longo de três anos (no mínimo), tendo como base a idade do aluno.

Os agentes participantes são, em sua maioria, jovens na faixa de 15 a 24 anos de idade, aproximadamente. A escola recebe alunos de Votuporanga(SP) e também de cidades vizinhas, como Cardoso, Cosmorama, Álvares Florence, Parisi, entre outras localidades.

Em geral, possuem nível socioeconômico médio e/ou elevado, vão até a escola de veículo próprio (levado pelos pais) ou ônibus (moradores de outros municípios). Apesar de possuir aproximadamente 150 matriculados nos diversos níveis do curso, optamos, nesta pesquisa, porrealizar a coleta das redações dos alunos do Nível B1.

\section{Coleta do CALI-TradHQ - Corpus de Aprendizes de Língua Inglesa - Tradução de História em Quadrinhos}

Inicialmente, o professor conversou com os estudantes acerca da importância da utilização de corpora como forma de compreender padrões léxico-gramaticais da língua-alvo.

\footnotetext{
${ }^{6}$ Do original: "The translation of comics is different from 'translation proper' not only because words co-exist with non-verbal systems, but also because verbal language in comics is only part - if sometimes the only visible part (i.e. over translation) - of what gets translated."
} 
Para exemplificar os itens mencionados, o professor projetou na tela da sala de aula algumas páginas de corpora on-line e corpus de texto traduzidos (corpus paralelo), tais como o Comet $^{7}$ e CorTrad ${ }^{8}$ (para exemplificar como é um corpus compilado, além de apresentar aos alunos algumas aplicabilidades de pesquisas em língua estrangeira com o uso deste recurso).

Dessa maneira, tendo os aprendizes compreendido o que é um corpus e o que são padrões lexicais, foi proposto o exercício de tradução da história em quadrinhos "O circo dos horrores", da revista da Turma da Mônica, edição 12, 2016.

Ao fim desta etapa, foram coletadas dez traduções do grupo escolar já citado, durante aulas regulares do curso nos meses de maio e junho de 2016.

\section{Dados Gerais sobre o Corpus estudado}

A história em quadrinhos foco deste artigo, "O circo dos horrores", possui uma tradução oficial em língua inglesa, The circus of horrors, publicada pelo Estúdio Maurício de Sousa. Foi publicada na edição de número 12, pela editora Panini, no ano de 2016. Conforme dito anteriormente, possui 871 tokens/329 types, ou seja, é constituída por 871 palavras totais e 329 formas sem repetição.

Posteriormente, os dados analisados foram separados em: Wordlist (formato que oferece dados estatísticos sobre as traduções) e Keywords (disponibiliza as palavras-chave que mais se destacaram em comparação com o corpus de referência - representativo da língua inglesa).

A título de ilustração, apresentamos abaixo uma tabela, na qual configuram as listas de palavras e listas de palavras-chave do texto vertido para o inglês pelo Estúdio Maurício de Sousa e do CALI-TradHQ:

7 COMET. Corpus Multilíngue para Ensino e Tradução. Disponível em:<http://comet. fflch.usp.br>. Acesso em: 8 maio 2016.

${ }^{8}$ CORTRAD. Corpus paralelo de Tradução (português-inglês) do COMET. Disponível em: <http://comet.fflch.usp.br/cortrad>. Acesso em: 8 maio 2016. 
Tabela 01 - Tradução oficial do Estúdio Maurício de Sousa

\begin{tabular}{|c|c|c|c|c|c|c|}
\hline \multicolumn{4}{|c|}{ WORDLIST } & \multicolumn{5}{c|}{ KEYWORD } \\
\hline $\mathbf{N}$ & WORD & FREQ. & $\mathbf{N}$ & KEY WORD & FREQ. & \% \\
\hline 1 & To & 40 & 1 & Smudge & 9 & 1.03 \\
\hline 2 & The & 28 & 2 & Circus & 9 & 1.03 \\
\hline 3 & You & 27 & 3 & Monica & 8 & 0.92 \\
\hline 4 & Is & 23 & 4 & Jimmy & 6 & 0.69 \\
\hline 5 & A & 22 & 5 & Tent & 5 & 0.57 \\
\hline 6 & I & 22 & 6 & Going & 12 & 1.38 \\
\hline 7 & This & 20 & 7 & Creature & 5 & 0.57 \\
\hline 8 & That & 15 & 8 & You & 27 & 3.10 \\
\hline 9 & It & 14 & 9 & Get & 12 & 1.38 \\
\hline 10 & Get & 12 & 10 & Plush & 3 & 0.34 \\
\hline
\end{tabular}

A primeira parte mostra a Wordlist das dez palavras mais usadas na história. Atestam para a existência de itens predominantemente gramaticais (expressos pelas preposições, artigos e pronomes), haja vista se tratar de uma lista de vocábulos mais frequentes.

Já a segunda parte (KeyWords) traz o rol de palavras mais significativas, contrastadas com o corpus de referência de língua inglesa BNC. Desta forma, temos, na grande maioria, a aparição de substantivos próprios - dos personagens e também do brinquedo de pelúcia da Mônica, subtendido pelo termo Plush (a palavra rabbit é a décima sétima desta relação, também com 3 ocorrências) justificando tratar-se da versão inglesa para "coelhinho".

Destacam-se ainda a presença do pronome pessoal you e do verbo get em ambas as listas, por se relacionarem diretamente aos sujeitos citados e às ações praticadas pelos protagonistas da história.

O item a seguir abordará os critérios para a realização das análises, e, posteriormente, os resultados da atividade de tradução feita pelos aprendizes.

\section{Análise dos dados}

A história em quadrinhos The circus of horrors possui vinte páginas. Segundo mencionamos, dez alunos traduziram a referida história, de modo que temos um total de aproximadamente quarenta e duas páginas de textos traduzidos. Os dados estatísticos do CALI-TradHQ, gerados pelo WordSmith Tools (SCOTT, 2012), versão 6.0, possibilitam 
uma melhor análise das traduções coletadas, com foco em alguns itens lexicais e expressões idiomáticas.

Com base nas informações geradas pelo programa, observamos a densidade lexical a partir do número global de palavras (nomeado tokens) e também do número de palavras diferentes (designada types).

Tabela 02 - Tokens e types do CALI-TradHQ

\begin{tabular}{|l|c|c|c|c|c|c|c|c|c|c|c|}
\hline & \multicolumn{7}{|c|}{ ALUNOS } & \\
\hline & $\mathbf{0 1}$ & $\mathbf{0 2}$ & $\mathbf{0 3}$ & $\mathbf{0 4}$ & $\mathbf{0 5}$ & $\mathbf{0 6}$ & $\mathbf{0 7}$ & $\mathbf{0 8}$ & $\mathbf{0 9}$ & $\mathbf{1 0}$ & $\begin{array}{c}\text { CALI- } \\
\text { TradHQ }\end{array}$ \\
\hline $\begin{array}{l}\text { TOKENS } \\
\text { (TOTAL) }\end{array}$ & 736 & 732 & 758 & 773 & 751 & 815 & 749 & 701 & 724 & 748 & 7500 \\
\hline $\begin{array}{l}\text { TYPES } \\
\text { (formas) }\end{array}$ & 291 & 277 & 285 & 300 & 282 & 303 & 270 & 282 & 292 & 302 & 644 \\
\hline
\end{tabular}

Observamos que os alunos, de modo geral, traduziram a história em quadrinhos utilizando menos palavras do que a versão oferecida pelo Estúdio Mauricio de Sousa (871 tokens/329 types), podendo indicar que houve menor variação lexical nos textos traduzidos dos alunos, em relação à tradução do Estúdio. Neste âmbito, o aluno 06 foi o que mais se aproximou do texto base - com 815 palavras totais e 303 formas.

Baseado no BNC Wordlist como corpus de referência da língua inglesa, geramos também uma lista de palavras-chave, a partir das quais, pudemos realizar a análise lexical do texto traduzido pelos alunos. Tabela 03 - Keywords CALI-TradHQ

\begin{tabular}{|c|c|c|c|}
\hline $\mathbf{N}^{\mathbf{0}}$ & Keyword & Freq. & $\mathbf{\%}$ \\
\hline 1 & CIRCUS & 94 & 1,25 \\
\hline 2 & MONICA & 71 & 0,95 \\
\hline 3 & SMUDGE & 59 & 0,79 \\
\hline 4 & MONSTER & 55 & 0,73 \\
\hline 5 & JIMMY & 49 & 0,65 \\
\hline 6 & BEAST & 33 & 0,44 \\
\hline 7 & I & 240 & 3,20 \\
\hline 8 & YOU & 209 & 2,79 \\
\hline 9 & CASCÃO & 16 & 0,21 \\
\hline 10 & THIS & 173 & 2,31 \\
\hline
\end{tabular}

No rol apresentado, há a referência aos personagens (tanto em inglês quanto em português), indicando que nem todos os discentes realizaram a tradução. Contudo, devido à frequência de Smudge (59 
v. 7 (1)

$141-159$ jan/jun 2017 ocorrências) e Jimmy (49 vezes) serem superiores aos seus respectivos nomes próprios ( $9 / 12$ eventos), inferimos que a maioria dos alunos efetuou a adaptação dos nomes dos protagonistas da história para o idioma pedido.

Tendo compilado a primeira fase do corpus paralelo CALITradHQ, selecionamos, para esta investigação, os seguintes itens ou padrões lexicais:

a. A tradução de dois itens lexicais:

- "fantasia";

- "coelhinho" (neste caso, espera-se por indicativos de que o brinquedo seja de pelúcia, a fim de que a tradução não perca a semântica deste item da personagem Mônica).

b. As opções tradutórias para as expressões:

- "Tirar o cavalinho da chuva"

- "Vai sobrar coelhada pra mim" - neste caso, a consideramos uma expressão idiomática no contexto em que foi criada;

- "O Sr. Sousa é pão duro"

Após a análise, os itens A e B contemplam os resultados em forma de porcentagem. Assim, apresentamos os aprendizes que conseguiram incorporar as nuances da língua inglesa satisfatoriamente, caracterizando uma compreensão global do idioma alvo.

Consequentemente, também indicamos o número dos alunos que traduziram as expressões individualmente ou ainda omitiram partes das expressões idiomáticas, resultando em lacunas linguísticas, conforme demonstra a próxima seção do corrente texto.

\section{Itens Lexicais}

Durante a exploração dos dados, foi considerada a hipótese de os alunos usarem termos equivalentes em suas traduções. Os gráficos a seguir demonstram essa possibilidade.

O item "fantasia" apresentou maior inadequação vocabular nas traduções dos aprendizes, pois uma das palavras equivalentes e adequada em língua inglesa, costume, ocorreu somente $40 \%$ no corpus, enquanto que a opção não apropriada para esse contexto, fantasy, uma vez que se trata de um cognato em inglês que não se refere a um disfarce, mas a algo ilusório, irreal, teve 60\% de frequência, conforme mostra o Gráfico 01, abaixo. 
Estas foram as possibilidades encontradas pelos discentes, embora houvesse também a opção tradutória disguise, utilizada pela tradução do estúdio e elencado no glossário da história ao final do gibi. Gráfico 01 - Escolhas lexicais para o termo "fantasia"

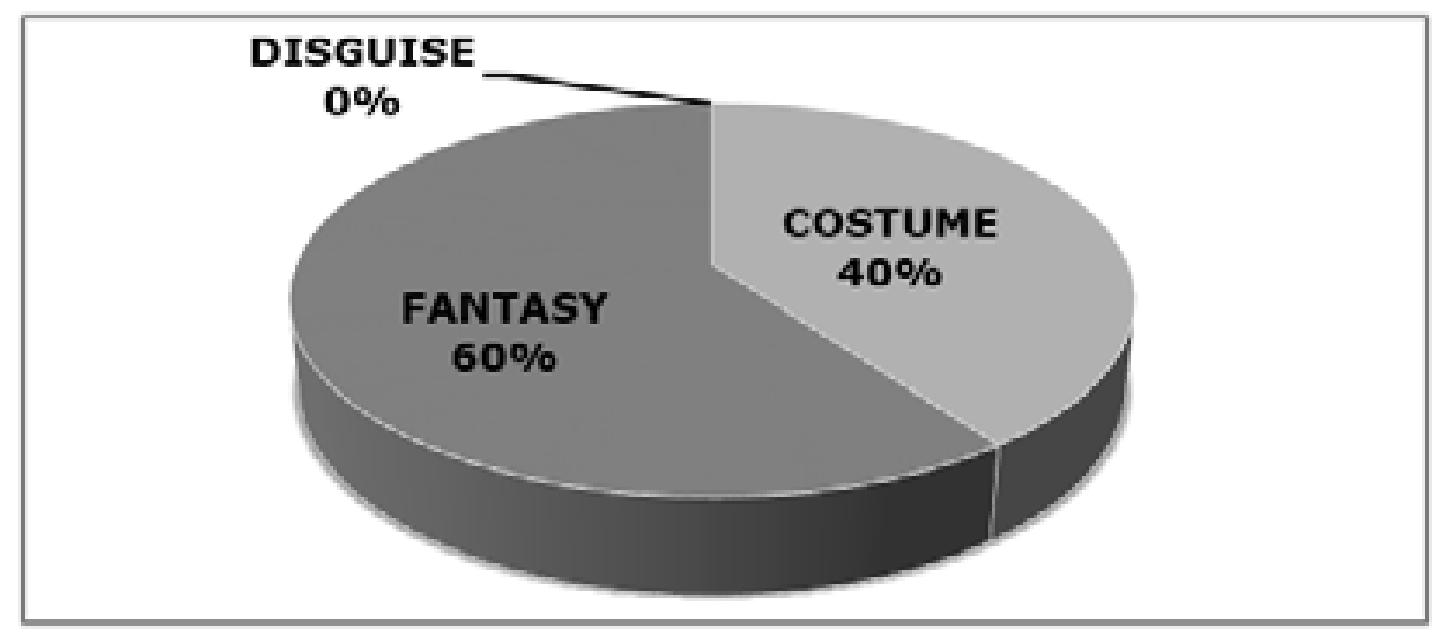

Já o termo "coelhinho" obteve uma variedade maior de opções tradutórias em relação ao item lexical anterior. Entre essas opções, podemos citar bunny (50\%), little rabbit (30\%), little bunny (10\%) e rabbit $(10 \%)$. Novamente, os alunos não esgotaram todas as possibilidades de tradução, pois a forma plush rabbit, opção tradutória da versão original, por exemplo, não foi mencionada, tampouco bunny rabbit, combinação bastante frequente em língua inglesa. Segue o Gráfico 02 com as escolhas lexicais elencadas:

Gráfico 02 - Escolhas lexicais para o termo "coelhinho"

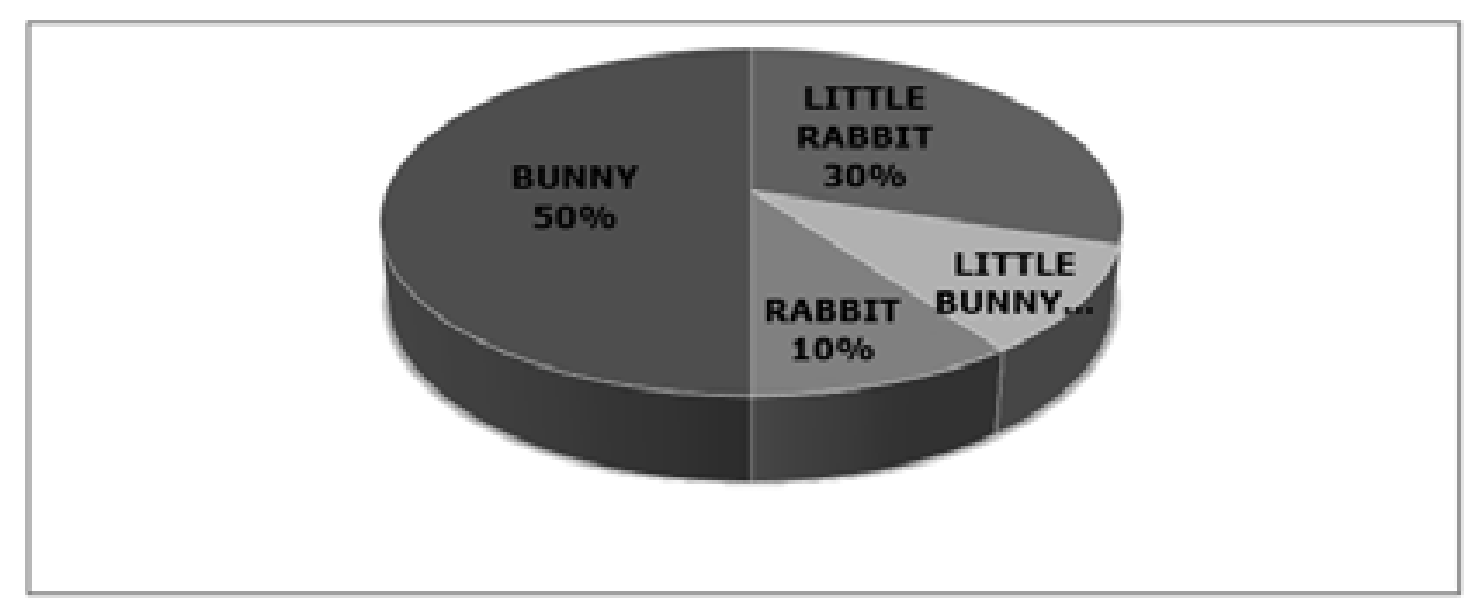

O desconhecimento do significado de plush rabbit por parte dos alunos pode ter comprometido a tradução, pois, na versão dos alunos, 
o vocábulo indicou um coelho de verdade, enquanto que plush rabbit refere-se especificamente ao coelhinho de pelúcia.

\section{Expressões Idiomáticas}

Nas traduções das expressões presentes nos quadrinhos selecionados para esta pesquisa e que compõem nosso corpus paralelo, ocorreram várias versões que podem ter alterado o sentido das fraseologias enfocadas. Neste tópico, as escolhas efetuadas pelos alunos, assim como a quantidade unitária de tais resultados estão dispostas em tabelas, enquanto que os comentários dos autores e a porcentagem se dão por intermédio de marcadores:

Tabela 04 - Tradução da expressão idiomática "pode tirar o seu cavalinho da chuva"

\begin{tabular}{|l|c|}
\hline \multicolumn{1}{|c|}{ TRADUÇÃO DOS ALUNOS } & QUANTIDADE \\
\hline Don't hold your breath on that one! & 01 \\
\hline You'd better have another thing coming & 01 \\
\hline No, don't hold your breath & 01 \\
\hline Don't hold your breath! & 01 \\
\hline I don't! You can give up this idea. & 01 \\
\hline No, can give! & 01 \\
\hline No & 01 \\
\hline No! You can take your little horse from the rain. & 01 \\
\hline No! You can remove the your horse of rain! & 01 \\
\hline Can take your rain horse! & 01 \\
\hline & $\mathbf{1 0}$ \\
\hline
\end{tabular}

- $20 \%$ dos estudantes mantiveram o sentido da expressão (Don't hold your breath on that one! / You'd better have another thing coming);

- 20\% utilizaram parte da expressão (No, don't hold your breath / Don't hold your breath!);

- 10\% simplificaram a expressão, mantendo parcialmente o significado original (I don't! You can give up this idea.);

- $10 \%$ efetuaram a versão utilizando um verbo e sem nenhum resgate da idiomaticidade da expressão original, alterando, desse modo, a compreensão da sentença (No, can give!);

- $10 \%$ traduziram toda a sequência em uma única palavra (No), perdendo o sentido da sentença, uma vez que não conseguiu traduzi-la; 
- 30\% traduziram literalmente, e erroneamente, utilizando o vocábulo horse, novamente perdendo totalmente a idiomaticidade da expressão original e sem significado algum na língua-alvo (No! You can take your little horse from the rain. / No! You can remove the your horse of rain! / Can take your rain horse!).

A tabela a seguir apresenta as traduções da expressão idiomática "pão duro", em "O Sr. Sousa é pão duro":

Tabela 05 - Tradução da expressão idiomática "pão duro"

\begin{tabular}{|l|c|}
\hline \multicolumn{1}{|c|}{ TRADUÇÃO DOS ALUNOS } & QUANTIDADE \\
\hline Mr. Souza is very cheapskate! & 01 \\
\hline Mr. Souza is very tight-fisted & 02 \\
\hline The Mr. Souza is very not spend money! / miser & 01 \\
\hline Mr. Sousa is very miser! & 01 \\
\hline The Mr. Sousa is very wrist! & 01 \\
\hline The Mr. Sousa is very cheap! & 01 \\
\hline The Sr. Sousa is much! & 01 \\
\hline The Mr. Sousa is very... & 01 \\
\hline Omitiu a expressão (não traduziu esta frase) & 01 \\
\hline & $\mathbf{1 0}$ \\
\hline
\end{tabular}

- 30\% dos estudantes conseguiram efetivar uma versão adequada com o significado total da sentença (Mr. Souza is very cheapskate / Mr. Souza is very tight-fisted);

- 20\% ofereceram opções sem sentido na língua-alvo (The Mr. Souza is very not spend money! / Mr. Sousa is very miser!);

- 30\% utilizaram termos equivocados, trazendo uma interpretação errônea da oração e totalmente sem sentido na língua-alvo (The Mr. Sousa is very wrist! / The Mr. Sousa is very cheap! / The Sr. Sousa is much!);

- 20\% omitiram a expressão, perdendo, assim, a semântica do quadrinho (The Mr. Sousa is very...), pelo fato de não saberem qual usar.

Na tabela 6 abaixo, apresentamos as traduções da expressão idiomática "Vai sobrar coelhada pra mim": 
v. 7 (1)

$141-159$ jan/jun 2017

Tabela 06 - Tradução da expressão idiomática "vai sobrar coelhada pra mim"

\begin{tabular}{|l|c|}
\hline \multicolumn{1}{|c|}{ TRADUÇÃO DOS ALUNOS } & QUANTIDADE \\
\hline Bunnying & 01 \\
\hline Monica will end up finding and she will beat with rabbit in me! & 01 \\
\hline Monica will end up finding and she will beat with rabbit me! & 01 \\
\hline The Monica will end up discovering. And will be left to me. & 01 \\
\hline The Monica will end up finding... And will remain to me! & 01 \\
\hline The Monica will finish finding and will beat me. & 01 \\
\hline And I will be taking those bunny hits! & 01 \\
\hline Monica went to get the bunny and... & 01 \\
\hline Monica will end up discovering... And will be left coelhada for me! & 01 \\
\hline Monica will end up finding. & 01 \\
\hline \multicolumn{1}{|c|}{ Total } & $\mathbf{1 0}$ \\
\hline
\end{tabular}

- 30\% tentaram traduzir, com algumas notórias incoerências léxico-gramaticais, desconsiderando, também, o objeto da agressão (The Monica will finish finding and will beat me./ The Monica will end up discovering. And will be left to me. / The Monica will end up finding... And will remain to me!);

- 10\% dos estudantes criaram um item lexical, bunnying, cujo significado não tem relação com aquele do contexto enfocado;

- $10 \%$ traduziram com muita propriedade, adicionando o coelho na tradução (And I will be taking those bunny hits!);

- 20\% não traduziram o coelho como pelúcia, alterando o sentido do contexto (Monica will end up finding and she will beat with rabbit in me! / Monica will end up finding and she will beat with rabbit me!);

- $10 \%$ transcreveram a expressão em português, não realizando a tradução (Monica will end up discovering... And will be left coelhada for me!);

- $20 \%$ não terminaram a tradução da sentença ou omitiram o trecho (Monica went to get the bunny and.../ Monica will end up finding.), impedindo o entendimento do quadrinho.

Observamos que as escolhas adotadas pelos aprendizes nos textos são ecos da abordagem Gramática e Tradução, base do primeiro livro do curso. Embora as traduções utilizadas, como dito anteriormente, tenham sido recolhidas de alunos de módulos intermediários, estes 
tendem a repetir a tradução sistemática e pouco funcional realizadas nos drills, típica estratégia de aprendizagem desta abordagem.

Vale ressaltar que a análise aqui apresentada não teve como propósito atribuir juízo de valor às traduções dos aprendizes, mas, sim, buscou examinar suas escolhas lexicais durante o processo, bem como levantou hipóteses para tais decisões. Além disso, os resultados aqui mostrados foram também disponibilizados e discutidos com os alunos, a fim de chamar a atenção para a importância de uma abordagem lexical e baseada em corpus no aprendizado de uma LE.

\section{Considerações finais}

Os resultados da análise dos dados do CALI-TradHQ indicam que os aprendizes acabaram transferindo os padrões da língua portuguesa ao traduzir os quadrinhos para a inglesa, incorrendo em equívocos, conforme destacados ao longo do artigo.Essas ocorrências, comprovadas pelas análises no programa WordSmith Tools, podem ter comprometido o entendimento da história após sua tradução em língua inglesa, pois nem mesmo os elementos pictóricos conseguiram recuperar o sentido ou a intenção que o texto deveria expressar.

No presente artigo, foi relatada apenas uma das inúmeras possibilidades de pesquisa com a utilização de corpora. Devido ao recorte do tema, não foi possível pesquisar outros aspectos interessantes para pesquisas em corpora, tal como comparar a tradução oferecida pelo estúdio da empresa que efetuou a versão da história e a proposição de atividades didáticas a partir do CALI-TradHQ, visando sanar ou diminuir as dificuldades apresentadas pelos estudantes.Essa investigação seguramente será realizada, após ampliarmos o corpus de estudo em questão nos próximos meses.

Dessa maneira, espera-se que, com a crescente divulgação de tarefas e aulas fundamentadas neste prisma, surjam novos horizontes para a aprendizagem, com a efetivação dos objetivos propostos para o ensino de LE em nosso país a partir de corpora. Além disso, como perspectivas futuras, o CALI-TradHQ será ampliado, segundo mencionamos, uma vez que outras turmas realizarão traduções da mesma história e de outras que já selecionamos para atividades de tradução.

Dessa forma, a aprendizagem e a avaliação de LE com o uso de corpora, sob uma perspectiva lexical, poderão ser mais comumente 
v. 7 (1)

141-159 jan/jun 2017

usadas como um recurso adicional, proporcionando uma investigação para os interessados na aquisição do segundo idioma, visto que os resultados da análise poderão ser discutidos, rumando a novos patamares no universo da linguagem e no aprendizado de uma LE sob a ótica da LC e de uma abordagem com foco no léxico.

\section{Referências}

BARBOSA, A.; VERGUEIRO, W. (Orgs.). Como usar as histórias em quadrinhos em sala de aula. São Paulo: Contexto, 2004.

FRANKENBERG-GARCIA, A. Compilação e uso de corpora paralelos. In: TAGNIN, S. E. O.; VALE, O. A. Avanços da Linguística de Corpus no Brasil. São Paulo: Humanitas, 2008, p. 117-136.

GRANGER, S.; TRIBBLE, C. Learner corpus data in the foreign language classroom: Form focused instruction and data driven learning. In: GRANGER, S. (Ed.). Learner English on Computer. London: Longman, 1998. p.199-209.

LEECH, G. Preface - Learner corpora: What they are and what can be done with them. In: GRANGER S. Learner English on Computer. London and New York: Longman, 1998. p. XIV - XX.

McENERY, T.; WILSON, A. Corpus Linguistics. Edinburgh: Edinburgh University Press, 1997.

ORENHA-OTTAIANO, A. Learning and teaching collocations through an Online English Collocations Workbook. In: Vocab@Tokyo, 2016, Tóquio. Vocab@ Tokyo Conference Handbook, 2016. p. 59-60.

Compilação de um corpus de aprendizes de tradução e análise de aspectos colocacionais. In: ABRALIN EM CENA, 2012, Cuiabá. Anais do Abralin, 2012.

ORENHA-OTTAIANO, A.; ROCHA, J. M. P. Ensino de inglês como LE e contribuições pedagógicas de um glossário bilíngue de colocações. Revista Signótica, v. 27, p. 485-509, 2015.

RICHARDS, J. C.; RODGERS T.S. Approaches and Methods in Language Teaching. Cambridge: Cambridge University Press, 1986.

SCOTT, M. WordSmith Tools. Versão 6.0. Oxford: Oxford University Press, 2012.

SINCLAIR, J. M. Corpus, Concordance, Collocation. Oxford: Oxford University Press, 1991.

SOUSA, M. de. Mônica and friends: The circus of horrors. n. 12. Barueri: Panini, 2016. 68 pages. 
TRIBBLE, C. Concordancing and an EAP writing programme. CÆLLL Journal, V.1, n.2, p.10-15, 1990.

VENTURI, M. A. Aquisição de língua estrangeira numa perspectiva de estudos aplicados. Ed. Contexto: São Paulo, 2006.

VIANA, V. Linguística de Corpus: conceitos, técnicas \& análises. In: VIANA, V.; TAGNIN, S. E. O. (Orgs.). Corpora no ensino de línguas estrangeiras. São Paulo: Hub Editorial, 2010. p. 25-96.

ZANETTIN, F. Comics in Translation: An Overview. In: ZANETTIN, F. (ed). Comics in Translation. Ed. Manchester: St. Jerome, 2009.

Recebido em: 08 de fev. de 2017.

Aceito em: 13 de jul. de 2017. 